ARTICLE

\title{
Hunger by the Sea: Partnerships in the Brave Third Space
}

Xue Han, *Julian McDougall, Charlie Mott and Sue Sudbury, Faculty of Media and Communications, Bournemouth University, UK

Contact: imcdougall@bournemouth.ac.uk

\section{ABSTRACT}

In this article, co-authored by two undergraduate students (one international) and two academics in a media faculty of a post-92 university (e.g., Polytechnic), in England, we share the findings and offer a reflexive lens on the process of a media practice education collaboration in the community, through the co-production of the animated film Hunger by the Sea: https://vimeo.com/234840520 . The contributors to this research are media practice academics, media and journalism students from related but distinct disciplines, and the users and providers of a food bank on the English coast. The food bank users and providers have not been involved in this writing, but their voices are (literally) heard in the project's primary outcome-the animated film. In this article, we articulate reflections on how the project, in bringing together academics, students, and community participants in a challenging but rich space, enabled exchanges of expertise and new, boundary-crossing ways of being in education that can be discussed as "third space" interactions.

KEYWORDS

Media production, third space, animation, community, co-creation

Figure 1: Hunger by the Sea

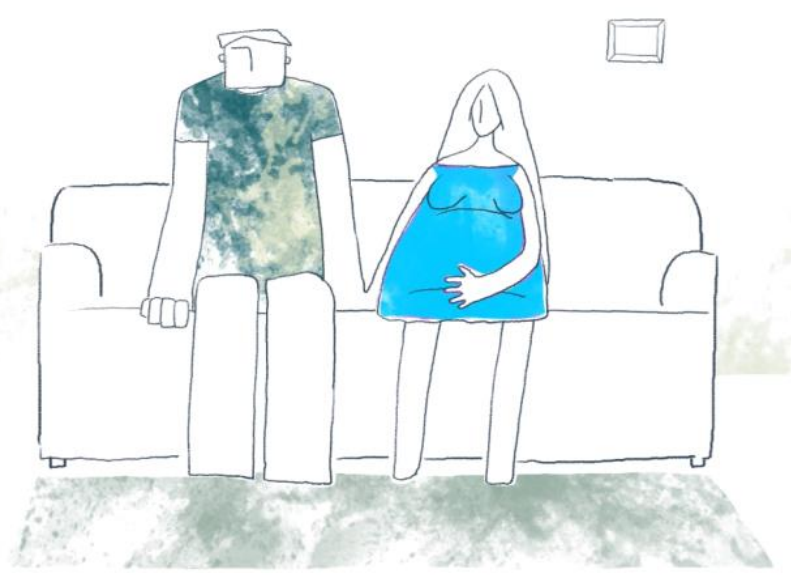

Figure 1: Source: Sue Sudbury

CC-BY Licence 4.0 This is an Open Access article distributed under the terms of the Creative Commons - Attribution License 4.0 International (https://creativecommons.org/licenses/by/4.0/), which permits unrestricted use, distribution, and reproduction in any medium, provided the original work is properly attributed. 


\section{THE PROJECT}

This is a partnership between two academics and two students, and the providers and users of a food bank. The academics are a documentary maker teaching a media production course (Sue) and a researcher in pedagogy and media practice (Julian). Sue led the project and recruited two undergraduate students, one from journalism (Charlie) and the other from Animation (Xue). In this article, consistent with the conceptual framing of Students as Partners (SaP), a collective voice (we) is used for the majority of our account and reflections, but where perspectives are specific to role or individual, the voice is presented as singular.

This media practice partnership was linked to the university's Student Research Assistant (SRA) scheme, which Sue applied to. The first application was for a student (Charlie) to work on a participatory video project with food bank users. Subsequently, the first phase of the research led to a change of plan, requiring animation rather than documentary video as the practice research mode, so Sue applied for a second SRA to make the animated film. Each SRA would be paid ten pounds an hour for a maximum of 120 hours. The SRAs applied in response to an advertisement on the university's student portal. Only students with average marks of $70 \%$ and above could apply, as part of the university criteria. Whilst the criteria limited the potential reach of the partnership, the fact that students were paid made Sue feel far more comfortable with the partnership as a working relationship, from her experience as a media practitioner.

This project framed established lines of enquiry into partnership and co-creation (Marquis et al., 2016; Healey, Flint, \& Harrington, 2016) with the concept of the third space (Bhabha, 1994). The third space has been of interest for the pursuit of designing pedagogy for equity and social justice. Gutiérrez (2008) offered the third space as a way to think about the social actors in a given setting, their autobiographical and temporal specificities, and how these could be accounted for in the design of an emancipatory form of educational experience. Third spaces in higher education have the potential to foster co-creation through porous expertise (Potter \& McDougall, 2017). This porosity addresses the question of whose knowledge counts and how boundaries of expertise can be negotiated formally and informally across and between various knowledge domains. This is achieved through more curational, negotiated, reflexive, and inter-disciplinary forms of pedagogy.

With regard to university learning and teaching, the first space is home/community/family, the second space is the university, and the third space can be a physical, metaphorical, or digital/virtual space (or a combination of these), which is in between the first and second; whilst this can be a physical space, it is more importantly a space for thinking and working differently. For this project, we are not claiming the food bank as a third space, but we are suggesting that the way we worked in partnership was indicative of a third space in which pedagogy is negotiated and in which different forms of knowledge are acknowledged and validated. The signature pedagogies in these spaces are qualitatively different because they demand that the values and the culture of the participants feature in the space. Third spaces are, therefore, in significant ways, contested, negotiated, political spaces in which students are positioned in partnership with educators. Finally, from this project, we are also looking ahead to another second space, the media workplace, where our student partners are now working and have worked in the past. The transformative experiences we observe from this project will, we hope, impact on this 'second second space.' 
Figure 2: Recruiting the student partners

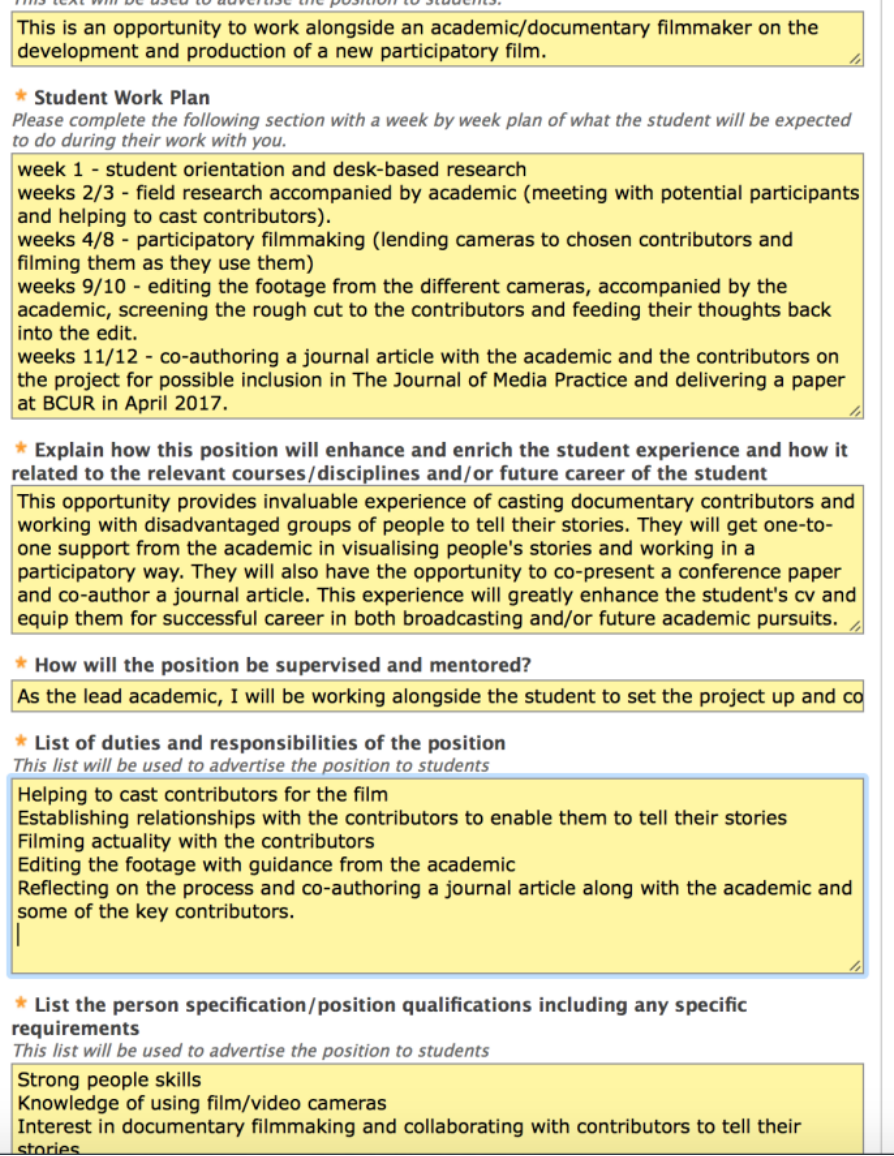

Figure 2: Source: Sue Sudbury

\section{THE SETTING}

The Trussell Trust is a UK charity which runs a network of over 400 food banks. In recent years, austerity economics and reforms to social security benefits have led to a significant increase in the use of food banks by people in work as well as the unemployed. In the year before the project, its 424 food banks gave out three-day emergency food packages to 1.3 million people-double the number of people who were needing to use food banks five years ago.

By asking people who use a food bank to participate in the production of an animated film sharing experiences from their everyday lives, this project sought to provide users with opportunities to speak directly to policymakers and politicians, and to selfrepresent, informed by ethnographic principles. However, we make no dubious or potentially exploitative claims for the food bank as a third space. The research presented here is restricted to a focus on the experiences of students and academics in a new kind of partnership and on the research outputs as existing in a third space across and between this written-up article and the visual media it speaks to. Converging the established field of SaP with our interest in third space, and as SaP and digital literacy initiatives both progress to maturation in Higher Education (HE), as the inception of this journal suggests, we are obliged to reflect on their transformative and redistributive impacts:

- What happens to students and teachers working as partners -in a (digital media) third space?

- What impact might this have on the second spaces of the university and the workplace (in this case, the media)? 


\section{THE APPROACH}

In our exploration of the process and outcomes, we describe the distinct nature of the food bank project and hypothesise that SaP can take back to their second spaces those rich experiences that disrupt apparently neutral functional and economic discourses about why we are learning in digital media spaces as opposed to what we are learning. In this way we accept and embrace that a students-as-partners approach requires "a multiplicity of practices predicated on power-sharing and reflectivity from all involved, which can make partnership challenging to enact" (Matthews, 2017, p. 6).

\section{THE FIELD}

Readers of the International Journal for Students as Partners (IJSaP) will be familiar with the core principles of partnership that inform the community of practice it speaks to, for, and with. As SaP is an emerging research field, approaching a maturation phase, a number of sub-fields have developed, among and across which, we will situate our research.

SaP as a strategic response to the need to repurpose "student engagement" through embedding partnerships in institutional cultures is a values driven and "troublesome" threshold concept (Cook-Sather, 2014, p. 186). Student engagement is an endemic concern as the identity of $\mathrm{HE}$, potentially in crisis, is re-negotiated, and $\mathrm{SaP}$ is presented as both a macro-level response, extending stakeholder relationships into industry and community, and a micro-level "way of doing" (Healey, Flint, \& Harrington, 2016, with outcomes usually disseminated within an action research and/or case study framework. Consider Shaw et al's reflections on how "The words used by students to describe the experience shifted from "painful," "challenging," and "frustrating" pre-SaP to "successful," "productive," and "fun" post-SaP." (2017, p. 6).

Research into SaP distinguishes loose classifications (Bernstein, 1996) of this approach from genuine practice, which fosters collaboration across the whole institution, with some key shared principles (Matthews, 2017): inclusive and ethical partnerships for transformation; power-sharing relationships and uncertain outcomes, although we might see the more ethnographic flavour of embracing uncertainty and the objective to transform as a site of tension. This sub-field draws heavily on Freire (1970) and the desire for 'praxis'. Crucial to this is the clear awareness of, and strategic resistance to, the adoption of SaP as a reproducing technology of the self, so that the 'uses of SaP' are always a site of struggle:

The risk for SaP is that it becomes appropriated for neoliberal purposes that shift the discourse of SaP from a relational process to one of achieving outcomes of student satisfaction (which has been observed in terms of student engagement). In this scenario, the language of $\mathrm{SaP}$ is adopted, while the practices become "watered down" to ensure particular outcomes that maintain the power structures that SaP seek to disrupt (Matthews, 2017, p. 5).

However, research shows that this broadly Freirian aspiration for SaP is often impeded by an underestimation of power (Kehler, Verwoord, \& Smith, 2017). Research into $\mathrm{SaP}$ is usually presented-as with our work here-by its protagonists, claiming agency and speaking to an emancipatory discourse. The workings of power and authority on the part of those driving the intervention are often annexed with the students' voices reduced to data. Avoiding this trap requires "a willingness to be mindful about the layers of power in our respective positions..., a personal commitment to mindfulness, vulnerability, and a 
willingness to change. Most importantly, SaP is a lived process that must engage the heart." (Kehler, Verwoord, \& Smith, 2017, p. 12).

Using a privileged lecturer-researcher voice on partnership in scholarly work might be viewed as manifesting a number of institutional framing processes-article authorship, research conventions, funding and research metrics combine to restrict opportunities for meaningful giving over of power or more transformative inexpertise (Rancière, 1991). But SaP research also bears witness to more overt and willful resistance, particularly in curriculum design and development. Murphy et al. (2017) indicates that academic staff are signed up to the spirit of SaP but articulate a series of disclaimers about whether all students are sufficiently "engaged" to work as equals in decision-making and sufficiently "expert" in terms of curriculum:

Almost everything that was said about working in partnership was prefixed with a "but," showing that staff felt the idea had merit but that delivering on this merit was not perceived to be simple. The "but" in staff's otherwise positive view of partnership was also due to the perceived lack of engagement and subject awareness of the students (Murphy et al., 2017, p. 12).

For a more developed and systematic literature review of Students as Partners in $\mathrm{HE}$, see Mercer-Mapstone, L., Dvorakova, L. S., Matthews, K. E., Abbot, S., Cheng, B., Felten, P., Knorr, K., Marquis, E., Shammas, R., \& Swaim, K. (2017). For our purposes here, we can return to the shared Freirian principles of inclusive and ethical partnerships, power-sharing, and transformation, and we can be mindful of problems in the field, such as the underrepresentation of cross-disciplinary initiatives, the lack of evidence of partnership extending beyond staff and student collaboration within the university, the focus on impacts on individuals as opposed to institutional cultures, the lack of scale in published studies, low rates of staff-student co-authorship and, related to this, the absence of student-centric reporting of research and an over-emphasis on positive outcomes. Addressing some of these issues was a key objective for our project.

Our partnership students and staff, and a food bank and its users took us to the heart of ethics and power, and very different, at times conflicting, transformations. A key line of our enquiry is the inter-disciplinary and sub-disciplinary key learnings that took place for all of us. We are open about the problems encountered in the "brave space" and you are reading a co-authored article drafted and edited by two students, one film-maker academic, and one practice researcher, which we intend to be student-centric. The area we can't explore, beyond tentative implications, is macro institutional culture, and we can't claim scale or generalizability from our "small story."

\section{THE PARTNERSHIP}

There have been several written academic studies on food banks in Britain and observational broadcast documentaries set in food banks in the north of England and Scotland (Britain's Hidden Hungry, BBC, 2012 and The Food Bank: Scotland's Hidden Hunger, $B B C, 2015)$. However, there has been no research carried out where food bank clients are given cameras, where subjects become first-person storytellers, so this research was conceived as a participatory film-making project with users of a food bank addressing narratives of poverty with marginalised groups.

After Charlie spent several weeks volunteering in three local food banks, it became clear that people using food banks frequently had chaotic lives, struggling to make ends 
meet, with benefit changes and/or low-paid work, and the prospect of using cameras was too difficult. Responding to this problem, the project was repurposed as an animated film in which users could speak anonymously, and we recruited another student co-researcher, Xue, from the animation department. Even with this new plan, it took approaches to fourteen different food banks before finding one that was prepared to let us record users' voices.

This is the first time Sue had co-researched with students, and it was an enriching experience, with cross-faculty participants working in an interdisciplinary way to facilitate genuinely reciprocal learning. Working alongside a professional filmmaker, editor, and sound designer, the journalism, animation, sound design and radio production students learned industry practice in a real-life setting.

The four-minute animated documentary, Hunger by the Sea, is a practice output of this research, presenting the human voice of food bank clients to policymakers and government officials. It was shortlisted for the 2017 Arts and Humanities Research Council Research in Film Award in the "Innovation" category at the British Academy of Film and Television Arts; it won an Award of Merit in the Best Short Film Awards and was screened at the London International Documentary Festival. Film director Ken Loach, whose I, Daniel Blake had been an influence for this project, said of Hunger by the Sea, "with originality this film tells a shocking story with great sensitivity. It's a very well-judged and paced film that really draws you in. A delicate piece that makes the awfulness of people's predicament all the more shaming" (2017). The charity Feeding Britain, set up by the All-Party Parliamentary Group on Hunger, feature the film on their website, so this example of a students-aspartners project has the potential for impact at a national level (see https://www.feedingbritain.org/ ).

Sue and Julian had both watched I, Daniel Blake and been very moved by the food bank scene and were thinking about whether scenes like this were playing out in the real world, as the film suggests. The university was recruiting student research assistants, and this was an ideal way to fund a project of this kind. The way Sue had worked for a previous third voice project, Village Tales, with women in India (Sudbury, 2016), would be taken into a food bank, working in a participatory relationship with users of the food bank. There had been some very good observational documentaries about food bank users, but the powerful dimension of subjects authoring their own stories had not been attempted hitherto. Three food banks agreed initially, and Charlie, an undergraduate journalism student, was recruited to work as creative partner. Charlie began by volunteering in the three food banks to understand the operational realities of the setting and hear the stories of the users, so he was the researcher, as he had been on previous broadcast productions for his degree and outside of his studies. He slotted in easily to that role and to the meetings with Sue, working as director, to share his findings and, crucially, to discuss the lack of willingness on the part of the users to go with the initial plan - to take the camera and produce a video diary. We had assumed, from existing documentaries, that people would be able to understand their situation in a political context, but we had not anticipated the amount of shame people would be feeling in the local setting (about their low income, difficulties in managing their finances, the need to ask for help) and the prevalent internalisation of neo-liberal ways of thinking about this being their fault and a feeling that they should be doing better. We tried to keep our own political feelings in abeyance, working with an open mind and listening in the field. 
Whilst changing the plan in response to Charlie's research was not a significant shift from previous professional media practice, Sue had never worked with students in this way before; working with a current student as a researcher, outside of the classroom, with such a large degree of autonomy and trust. This was a hybrid project, coming out of the academy with a new configuration of expertise and knowledge building. Sue was in a different position, realising the only way the film could be made to give voice would be through animation, as this would maintain the participant voice but with the safeguarding distance of the drawings and the removal of the physical and emotional burden of the filmmaking. Contingent factors enabled us to recruit a second student assistant, Xue, from a vacancy elsewhere, from the animation department. This was where the learning began in earnest for Sue-as she had never worked on animation before-and for all of us, because on one visit by Charlie and Sue to the food bank, the users that happened to be there on that day and were prepared to be recorded offered an abundance of stories that would normally take several trips to harvest.

Charlie's prior experience in the research phase helped with trust building; he spoke the language and understood the context of the stories recorded. Sue, as producer/director, left the room for the recordings, something that would not happen in the industry, which hands over a high level of trust to the student, who in this moment was more expert than the academic. This, in turn, enabled a higher level of trust between the student and the users than would have been the case had the more experienced, but less familiar, academic (Sue) been present. Sue used her experience and expertise as a documentary maker to decide that it was less intimidating for the interviewee if only one person was present, and Charlie had volunteered in food banks up until this point, so he was familiar with the subject-it was a partnership of porous expertise.

With the researcher (Charlie) recording the voices without the director (Sue) present, Sue was dependent on Charlie's knowledge of context when working with sound without pictures. When the animator (Xue) joined the project, Sue and Xue worked together, discussing metaphorical images and their connections to the recordings (e.g., red lines around a seaside helter-skelter tightening to connote red tape). Sue hadn't previously appreciated the complexity of, or time required to, realise animation; when Xue joined the project, she brought a vision and expertise from previous award-winning work, but again, Sue's handing over of trust and relinquishing control of the piece were key shifts in the pedagogic relation. In the final stages, a radio production student was also recruited to work on aspects of audio editing.

It's important to emphasise distinctions and nuances between documentary filmmaking, animation, and audio production. Partnership and collaboration across these domains is about more than just converging different aspects of media. Sue was constantly trying to grasp what Xue's work involved and whether this was beyond the expectations of the project. Xue had never worked on a documentary before and is now developing a postgraduate proposal in the area. Whilst Charlie enjoyed more autonomy than is usually the case when researching for a director, the final cut excluded one story he was keen to see in the film, so the power dynamics of the production relations were restored. With our third-space metaphor in mind, the nature of this partnership as generally fragmented in space and time is also key, with each element being transmitted digitally and Xue and Charlie never working in the same physical space. Finally, whilst Sue's instinct for storytelling through documentary film is in the DNA, her pedagogic modus operandi is less entrenched, so the shift here is less profound in one sense than it is in other SaP projects, 
perhaps, because the collaborative, agile, and creative working space is defined more by experience from media practice than media education.

\section{Figure 3: Animation storyboard}

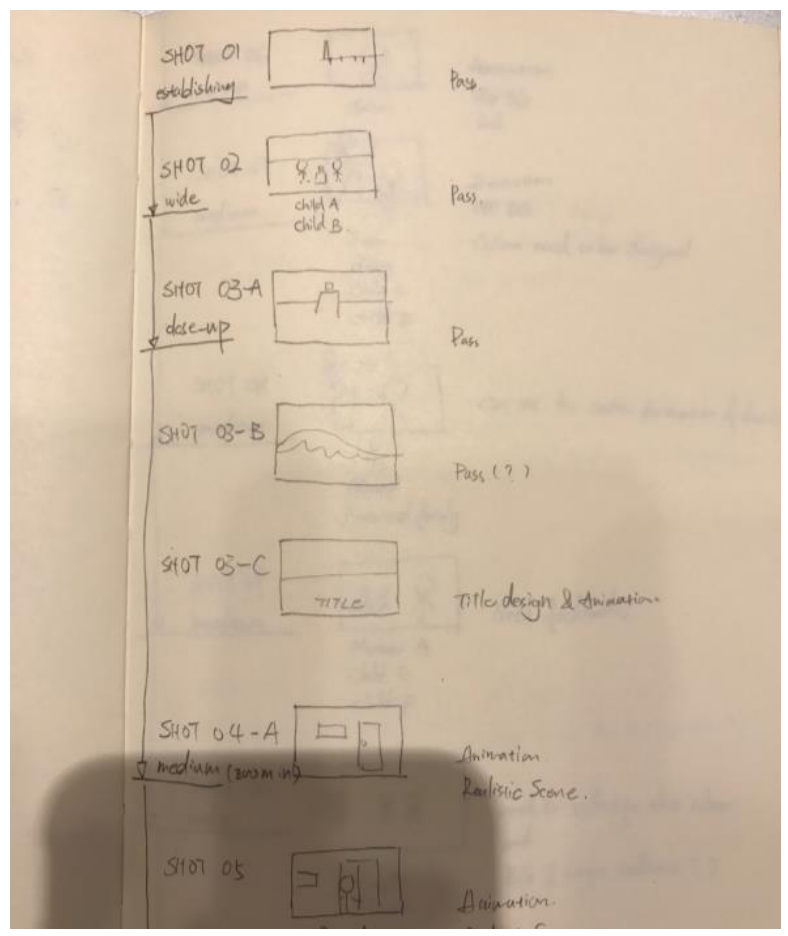

Figure 3: Source: Xue Han

\section{THE RESEARCH}

In this section we discuss two data sets-key extracts from the film, where the voices of our participants offer key thematic findings, and the students' production logs. The voice-over sequences combine captured audio from interactions in the food bank, along with extracts from the recorded interviews with both users and staff. Looking now at the production logs:

Charlie: I had a positive meeting with Sue. I think I understand her vision for the film. It's a great idea-participatory filmmaking for a misunderstood demographic. It's not really been done before. During our chat, I quickly realised that I don't know as much as I thought about the subject. I'll need to know more.

Xue: I am a student but I feel more like an artist working on this important project. My original intention [in] joining this project was only to accumulate many experiences, but I have learned far more than this. In my main course, our duty was to accomplish a commercial 3D project, graduate, and find a job. The working process was regularly following the CG industry. Compared with my main course, this project opened a new window to me. Firstly, I don't just focus here on how many exquisite details or realistic pictures I can make but more on how to build up the characters by just listening to their voice[s]. I need to close my eyes and imagine the people. Secondly, the project lets me know more about the UK and it makes me think about the society-how are people living outside our campus and our comfort zone? 
Do people have the same food problems in my hometown? Do we have an organization like a food bank? Both this project and my graduation project together helped me with my confidence. I know myself better. I know I can use multiple methods to work and I have better time management.

These extracts present a reflexive articulation of "known unknowns," but more importantly, these are very closely related to both the partnership with academics and the third space. Three key themes emerge, understanding and helping to form the vision of the teacher/director; feeling more like an artist than a student, and gaining confidence outside of the comfort zone. These are all facilitated both by the shift in working relationships and also by the third spaces-working with the misunderstood demographic in the food bank and the transition in media practices away from two second spaces - the vocational aspects of the degree curriculum and the previous experiences with the CG industry - the third space here is a fusion of these two second spaces with the food bank, but also enabled by the digital affordance of the virtual engagement with the users. The very different firstspace contexts are also part of the reflection.

Xue: Sue has been helping me, supporting me, and encouraging a lot. She provided me sufficient freedom to create. She treats me like a real artist, not only a student. This is the first animated documentary I participated in [making]. It means a lot to me. [First], animated documentary is still a controversial art form in my country. [Second], every single frame of the film is painted out from my hand. The process was like raising a baby, both toilsome and happy. All the other team members are like the other parents. At last, I win the challenge with a new technique. I'm a 3D student, and $3 D$ software is my regular tool. But in this case, I have to choose an efficient, quick and simple tool. I use Photoshop to finish all the shots, which I don't think [many animators are doing].

Charlie: As I don't really understand food banks, I've taken quite a bit of time to do some reading around the subject. It's amazing. The work of the volunteers and the generosity of the public. But it's got me angry-the arrogance of some politicians is gobsmacking in some cases. It just feels so pointless. These people shouldn't be getting hungry in the first place. Nevertheless, it's important to crack on. There are two amazing documentaries already out there by Vice and Panorama. Vice's is shot amazingly-it vividly captures the grit of a north-east food bank and the people that use it. However, Panorama's has real stories. We follow people who need the food bank and [see how] they'd do without it. I think we should concentrate on this. There could be some powerful stories behind closed doors.

In these reflections, two very different transformations from first and second spaces are presented. The baby metaphor emphasises the elevated levels of engagement in this partnership, compared to the "vertical discourse" (Bernstein, 1996) configurations of following the university course and/or industry training. The anger generated by this realworld learning is self-evident, but it appears to support our finding from previous research that both partnership and third-space learning initiatives are given more energy by a political premise than neoliberal employability framing. 
Charlie: Today was our first meeting with the Trussell Trust. It was really positive actually. The lady in charge is so passionate about what she does. It is clear this is a really complicated subject matter though, and she's also been let down in the past. I think Sue and I should keep this in mind.

Charlie: First days are always tough. Today was different though. I'll admit, I haven't done as much volunteering as I should have in the past, so my first day at the food bank was different. I did feel like I genuinely helped whilst keeping in mind our project. But I am worried. This wasn't quite what I thought it was going to be. The volunteers are GREAT but they aren't characters. For powerful films, we need good characters. It's also not TV friendly-it's a whitewashed, cold and sterile room. It feels like something from the Department of Work and Pensions.

Xue: The only regret is the pressing time. I thought it was an impossible mission when I knew Sue's target to finish a film; there was not much time when I joined, and there was only one animator, me. So this is really big pressure. However, Sue just kept her countenance and kept discussing things with me. She provides solutions in narrative, which inspires me a lot, and she suggests I use my previous animation working experiences. At the same time, team members who worked on the sound gave me

Charlie: wow. What a different world. Although the staff tell me this is the busiest food bank in the region, it still doesn't seem that busy. Here I am also finding problems. The people coming are here all the same sadly. They either have addiction or mental health issues I'm not denying they need the food bank, but it could be ethically challenging to involve them.. Giving them a camera and bringing them on board could provide problems. Although the staff here are really great too, I'm still a bit worried.

In these reports, we can observe the tensions between the need to develop as media practitioners - to embrace and join the Big Other of The Media (Bennett, Kendall, \& McDougall, 2012) and the ethical dimension of this - for example the distinction between volunteers and "characters."

Charlie: People don't want to be filmed. That's okay. I get it. Nor would I. BUT-that's a core theme gone from our documentary. Today, Sue came up with such a great idea. Anonymity via animation. Genius.

Xue Time is ticking away. My free time is increasingly being taken up by my dissertation and this is only going to get worse. So Sue has been working hard. She's made contact with a different food bank and we're going tomorrow.

These accounts from Charlie bring to the surface several "mission central" elements of partnership - the student and teacher are, at this point, in a relationship of equals, but the hierarchy reappears in the edit. Whether this is a return to the teacher-student hierarchy or director-researcher, or both, is harder to know, but the reflexive visibility of the partially inverted pedagogic relation (in Rancière's terms) is important, and the third-space context is fundamental to the issue-this is about more than just cutting out a part of a film, it's about deciding not to let a voice be heard-in this way, the process of editing footage 
mirrors the process of selecting research data from transcription and, quite possibly, the process of constructing knowledge (McDougall and Orr, 2018). Charlie and Sue were in dialogue after he left the project, as the audio recordings began to be visualised. In the case of the little boy's story, when Sue learned from Xue how long it takes to animate sequences, she realised it wasn't possible to include full stories, only sound bites. But the little boy's story was also a third-person account from the food bank manager, so Sue felt, as director, this was less impactful as the first-person sound bites.

Charlie: It feels weird handing over the project after so long and in such an unfinished state. Especially as I've never met the animator but I trust she's good. It's an odd feeling-picturing what you have in your head and imagining someone completely change that. This has been a great experience though. I feel my views have shifted and I understand more. I'm hopeful for change.

Xue: There were unexpected events during the process. The biggest one is some feedback on my graduation project came from my tutors. They asked me to add more elements to the shot, and each of them referred to a 3D software and new techniques. It could cost me a lot of time to solve and might take time from the animated documentary. At last, I dealt with some of them, left the rest to the destiny, and give every other second to this film. I slept less, but finally, I finished both of them!

These final extracts serve to re-emphasise the nature of this work as a third-space partnership. Xue and Charlie co-produced a film and co-authored an article with two academics, but the four of us have never met in the same place together. Xue describes the second and third spaces colliding, as she was forced to return to the second to react to tutor feedback at the same time as finishing this film. Whilst the distinctions between the usual "signature pedagogy" (McDougall \& Orr, 2018, p173) of media practice and our third-space partnership might be fine fault lines, the distinction between the reciprocal relations between the production team and this articulation of "they asked me to" is noteworthy.

\section{DISCUSSION}

Reviewing our outcomes in the framework of the maturing field of SaP, we return to the emerging themes above: interdisciplinary working; inclusive and ethical partnership; powersharing; challenges with uncertain outcomes in the "brave space"; and student-centric reporting. These themes are combined with our over-arching reflective questions about third-space partnerships:

- What happens to people doing education - as partners - in a (digital media) third space?

- What impact might this have on the second spaces of the university and the workplace-in this case, the media?

Working with students, as opposed to teaching them, is facilitated by the change of scene. To an extent this is just about going outside of the classroom and taking on different roles, but in this project, the addition of the food bank offered up a site for third-space relations, if not a third space in itself. The genuine not knowing, or the "known unknowns" of making this animation, were, for the academics, important; this was constructivist and enquiry-based learning in every way. Not only did the academics design the project and 
then hand over a great deal of responsibility for its execution, with very high stakes, ethically, but also, a student instigated the change of plan (away from video diaries) and another student realised the final product (animation); Sue, as director, was primarily the facilitator. Future research might take this further by involving SaP in the initial design of the project.

As explained above, the interdisciplinary aspects of this project should not be lost in a general perception of media. As noted earlier, there are clear and present shifts in the practice dynamics and disciplinary conventions - a film documentary maker producing animation, an animator working in new ways and on a documentary for the first time, and a film researcher handing over the sound to an animator without ever meeting - these are clear and present shifts in practice dynamics and disciplinary conventions. In industry a film researcher would never hand over sound to the animator as the director, as team leader, would always be the key team member liaising with different aspects of the production.

For the students, working in third space was key to the learning but, at times, frustrating. Using knowledge from both the first space - relationship skills learned from building relationships - and the second spaces (the university and media industry) enabled confident communication with contributors. For example, the importance of diplomatically excluding more vulnerable users on ethical grounds meant that skills from both the first and second spaces were required for the project to progress. With the shifts in ways of working as media producers arising from the process, the transformative impact of the project is likely to be taken back to the media second space instead of, or as well as, the university.

However, there are some important disclaimers. A stated challenge for the field of SaP would be to move away from positive reporting and, to some extent, the student coauthors here might be accentuating the positive. Furthermore, this is another small story, involving two students who were appointed to research assistant roles, for which the criteria were tough. Both the students had worked in media-industry contexts before, were academically successful, and thus, were confident operators in two second spaces. We cannot generalise from our experiences here, and it's clear that working in such an ethically charged third-space context would be impossible to scale and carries an abundance of risks, so this was a highly situated, specific, and carefully vetted partnership.

But, in concluding, we return to the political dimension. The purpose of the film in addressing the issue of poverty and the need for food banks to support the working poor in a rich country distinguished this project from co-creation initiatives seeking to enhance engagement or employability in neoliberal framings. Xue, as a parent herself, was affected greatly by a mother's story. Charlie was struck by his experiences in the research phase. As he says above, "It's got me angry!"

This is a "small story." However, it signals an original and significant intersection between two related conceptual fields - SaP and Third space. Further research is needed to develop the "threshold concept" of student partnership (see Cook-Sather, 2014, p6-7) to include the framing of the third space, along new lines of enquiry:

- The meaning, nature, and possibilities of facilitating partnership in third spaces;

- Educational strategies for working collaboratively in the third space;

- Suitable methodologies for investigating third-space partnership;

- Ethical and representational issues arising from the "writing up" of third-space partnership. 
- How the notion of the Third space might enrich, expand, or complicate thinking about partnerships.

This research was conducted with approval from the university's ethics committee, in full compliance with the university's research ethics code of practice and the British Educational Research Association's ethical good practice guidance.

\section{NOTE ON CONTRIBUTORS}

Xue Han is studying for MA 3D Computer Animation at Bournemouth University course and is keen to continue to explore her passion for making animation in different art styles. Xue was born in Xi'an and now lives in Shanghai. In her spare time she likes to practice Kongfu for health.

Julian McDougall is Professor in Media and Education, Head of the Centre for Excellence in Media Practice at Bournemouth University and Principal Fellow of the Higher Education Academy. He edits the journal Media Practice and Education, is Programme Leader for the Educational Doctorate in Creative and Media Education and convenes the annual International Media Education Summit.

Charlie Mott is a BA Multi-Media Journalism student at Bournemouth University who intends to pursue a career in television. To this end, he has been involved in a number of work experience placements in media environments as part of his course in addition to freelance work in the television industry during his holidays.

Sue Sudbury is a Principal Academic in the Faculty of Media and Communication at Bournemouth. Sue's film Village Tales won the 2016 AHRC Research in Film Award for Innovation and Hunger by the Sea was nominated for the same award in 2017. Sue is now leading Faculty initiatives to define and expand practice-based research.

\section{REFERENCES}

Aroa, B., \& Clemens, K. (2013). From safe spaces to brave spaces: a new way to frame dialogue around diversity and social justice. In L. Landreman (Ed.). The art of effective facilitation. (pp. 135-150) Sterling, VA: Stylus.

Bennett, P., Kendall, A., \& McDougall, J (2012). After the media: Culture and identity in the 21st century. London: Routledge.

Bernstein, B. (1996). Pedagogy, symbolic control and identity: Theory, research, critique. London: Taylor \& Francis.

Bhabha, H. (1994). The location of culture. London: Routledge.

Cliffe, A., Cook-Sather, A., Healey, M., Healey, R., Marquis, E., Matthews, K. E., MercerMapstone, L., Ntem, A., Puri, V., \& Woolmer, C. (2017). Launching a journal about and through Students as Partners. International Journal for Students as Partners, 1 (1): 1-9. 
Cook-Sather, A. (2014). Student-faculty partnership in explorations of pedagogical practice: a threshold concept in academic development. International Journal for Academic Development, 19(3), 186-198.

Freire, P. (1970). Pedagogy of the oppressed. New York: Continuum.

Gutiérrez, K. (2008). Developing a sociocritical literacy in the third space. Reading Research Quarterly, 43, 148-164.

Healey, M., Flint, A., \& Harrington, K. (2016). Students as partners: Reflections on a conceptual model. Teaching \& Learning Inquiry, 4(2). http://dx.doi.org/10.20343/teachlearninqu.4.2.3

Kehler, A., Verwoord, R., \& Smith, H. (2017). We are the Process: Reflections on the Underestimation of Power in Students as Partners in Practice. International Journal for Students as Partners, 1(1). https://doi.org/10.15173/ijsap.v1i1.3176

Loach, K. (2017). I, Daniel Blake. Producer: Rebecca O'Brien. UK: Sixteen Films.

Marquis, E., Puri, V., Wan, S., Ahmad, A., Goff, L., Knorr, K., Vassileva, I., \& Woo, J. (2016). Navigating the threshold of student-staff partnerships: A case study from an Ontario teaching and learning institute. International Journal for Academic Development, 21(1), 4-15. http://dx.doi.org/10.1080/1360144X.2015.1113538

Matthews, K. E. (2017). Five propositions for genuine Students as Partners practice. International Journal for Students as Partners, 1(2).

McDougall, J. \& Orr, S. (2018). Enquiry into learning and teaching in arts and creative practice. In E. Cleaver, M. Lintern, \& M. McLinden (Eds.). Teaching and learning in Higher Education: Disciplinary approaches to research (2nd ed.). London: Sage, 171187.

Mercer-Mapstone, L., Dvorakova, L. S., Matthews, K. E., Abbot, S., Cheng, B., Felten, P., Knorr, K., Marquis, E., Shammas, R., \& Swaim, K. (2017). A systematic literature review of Students as Partners in higher education. International Journal for Students as Partners, 1(1).

Murphy, B., Nixon, S., Brooman, S., \& Fearon, D. (2017). "I am wary of giving too much power to students": Addressing the "but" in the principle of staff-student partnership. International Journal for Students as Partners, 1(1).

Potter, J. \& McDougall, J. (2017). Digital media, culture and education: Theorising third space literacies. Basingstoke: Palgrave MacMillan.

Rancière, J. (1991). The ignorant schoolmaster: Five lessons in intellectual emancipation. California: Stanford University Press.

Shaw, N., Rueckert, C., Smith, J., Tredinnick, J., \& Lee, M. (2017). Students as Partners in the real world: A whole-institution approach, a whole of institution case study. International Journal for Students as Partners, 1(1).

Sudbury, S. (2016). Locating a 'third voice': participatory filmmaking and the everyday in rural India. Journal of Media Practice, 17(2\&3), 213-231.

Trussell Trust. Retrieved from https://www.trusselltrust.org/ 